\title{
Food Abundance Is the Main Determinant of High-Altitude Range Use in Snub-Nosed Monkeys
}

\author{
Cyril C. Grueter, ${ }^{1}$ Dayong Li, ${ }^{2}$ Baoping Ren, ${ }^{3}$ Zuofu Xiang, ${ }^{4}$ and Ming $\mathrm{Li}^{3}$ \\ ${ }^{1}$ School of Anatomy, Physiology and Human Biology, The University of Western Australia, Crawley, WA 6009, Australia \\ ${ }^{2}$ College of Life Sciences, China West Normal University, Nanchong 637002, China \\ ${ }^{3}$ Key Laboratory of Animal Ecology and Conservation Biology, Institute of Zoology, Chinese Academy of Sciences, \\ Beijing 100101, China \\ ${ }^{4}$ College of Life Science and Technology, Central South University of Forestry \& Technology, Changsha 410004, China
}

Correspondence should be addressed to Cyril C. Grueter, cyril.grueter@uwa.edu.au

Received 13 March 2012; Accepted 13 May 2012

Academic Editor: Randy J. Nelson

Copyright ( 12012 Cyril C. Grueter et al. This is an open access article distributed under the Creative Commons Attribution License, which permits unrestricted use, distribution, and reproduction in any medium, provided the original work is properly cited.

\begin{abstract}
High-altitude dwelling primates have to optimize navigating a space that contains both a vertical and horizontal component. Black-and-white or Yunnan snub-nosed monkeys (Rhinopithecus bieti) are extreme by primate standards in inhabiting relatively cold subalpine temperate forests at very high altitudes where large seasonal variation in climate and food availability is expected to profoundly modulate their ranging strategies so as to ensure a positive energy balance. A "semi-nomadic" group of $R$. biet $i$ was followed for 20 months in the montane Samage Forest, Baimaxueshan Nature Reserve, Yunnan, PRC, which consisted of evergreen conifers, oaks, and deciduous broadleaf trees. The aim of this study was to disentangle the effects of climate and phenology on patterns of altitudinal range use. Altitude used by the group ranged from a maximum of $3550 \mathrm{~m}$ in July 2007 to a minimum of $3060 \mathrm{~m}$ in April 2006. The proportional use of lichen, the monkeys' staple fallback food, in the diet explained more variation in monthly use of altitudes than climatic factors and availability of flush and fruit. The abundance of lichens at high altitudes, the lack of alternative foods in winter, and the need to satisfy the monkey's basal energetic requirements explain the effect of lichenivory on use of altitudes.
\end{abstract}

\section{Introduction}

An adaptive way for endotherm animals in montane temperate areas to cope with pronounced seasonality in climate and resource availability is to change location along an altitudinal gradient, thereby following food or avoiding cold/snow and ultimately maintaining a positive energy balance. Terrestrial herbivores, especially cervids, have been known to migrate to lower altitudes in winter $[1,2]$. Black-and-white snub-nosed monkeys (Rhinopithecus bieti) are semiarboreal colobine monkeys inhabiting subalpine temperate forests in Southwest China. Their association with such a highly seasonal, environmentally harsh, and primateatypical environment has sparked investigations on how they utilize their three-dimensional habitat.
Contrary to the expectation, however, none of the systematic studies on altitudinal ranging patterns in this species has delivered evidence for use of lower altitudes in winter [3-6]; see also [7, 8] for the ecologically and phylogenetically close Rhinopithecus brelichi and $R$. roxellana, resp.). This peculiarity required explanation, and Quan et al. [6] have recently proposed a sunshine hypothesis which posits that solar radiation affects the altitudinal distribution (and microhabitat use) of this species, primarily because it reduces costs of thermoregulation. A test of this hypothesis in a population of $R$. biet i in Tibet has shown that solar radiation and sunshine hours increase with elevation in Tibet, and intensified solar exposure was seen as the main reason for the monkeys' use of high altitudes in winter. However, Quan et al. [6] did not test a much more parsimonious 
prediction, that is that the abundance of winter foods is the main determinant of use of altitudes. The authors argued that the "monkeys food resources decrease with increasing elevation and also decrease in winter compared to other seasons." However, this statement is imprecise and misleading. It has been firmly established that at least for those populations of $R$. bieti that live at relatively high latitude, arboreal, and mainly fruticose lichens are a staple fallback food (sensu [9]), eaten throughout the year in large quantities and becoming an essential resource in winter when almost no fruit and no young foliage are available. At Xiaochangdu in Tibet, where the study of Quan et al. [6] was conducted, lichens make up $97 \%$ of the monkeys' winter diet [10], while at the slightly more productive site at Samage ca $200 \mathrm{~km}$ to the south they are $82 \%$ [11].

At both sites, the monkeys exploit other seasonally available foods in addition to lichens: young leaves are preferentially consumed in spring and fruits in summer (although fruit availability is lower at the more marginal site Xiaochangdu). While it may be true that preferred food, such as, fruits become rarer at higher altitude (cf. [12]), this is demonstrably not the case for lichens. Grueter et al. [11] have previously shown that arboreal lichen load increases with altitude at Samage, and Li et al. [4] have argued that this may be the main reason why the animals stayed at moderately high altitudes in winter and did not descend to lower altitudes. This finding seems highly intuitive and seems to reflect an adaptive strategy, as gaining access to a sufficient amount of fallback foods strongly influences survival chances $[13,14]$. Given their extreme reliance on one resource, it is therefore most prudent to assume that they use areas in winter where lichen density is highest.

In a previous paper, we compared use of altitude among seasons of one group of $R$. bieti over the course of one year [4]. Here we analyzed a larger data set (20 months) on range use, diet, phenology, and climate and tackle the question of determinants of altitude use in a multivariate way by simultaneously assessing the effects of several predictors (temperature, availability of seasonal foods, and dietary reliance lichens). Our results suggest that the relatively high abundance of lichens at high altitudes and the extreme dependence of the snub-nosed monkeys on these fallback foods determine their altitudinal patterns of winter ranging in a temperate habitat.

\section{Methods}

Field work was conducted on a large free-ranging group of snub-nosed monkeys ( $n=407$ members) in the Samage Forest (Baimaxueshan Nature Reserve) in Yunnan province, PRC $\left(27^{\circ} 34^{\prime} \mathrm{N}, 99^{\circ} 17^{\prime} \mathrm{E}\right)$, between September 2005 and July 2007. The site consists of evergreen conifers, oaks, and deciduous broadleaf trees. The study group occupied a wide range of altitudes, from $2600 \mathrm{~m}$ in the valley bottom to $4000 \mathrm{~m}$ near the summits of the mountains (Figure 1). Total annual rainfall (average of 2005/06 and 2006/07) was $1004 \mathrm{~mm}$, and mean annual temperature was $14.3^{\circ} \mathrm{C}$ at the research station at $2450 \mathrm{~m}$ (estimated to be around $10^{\circ} \mathrm{C}$

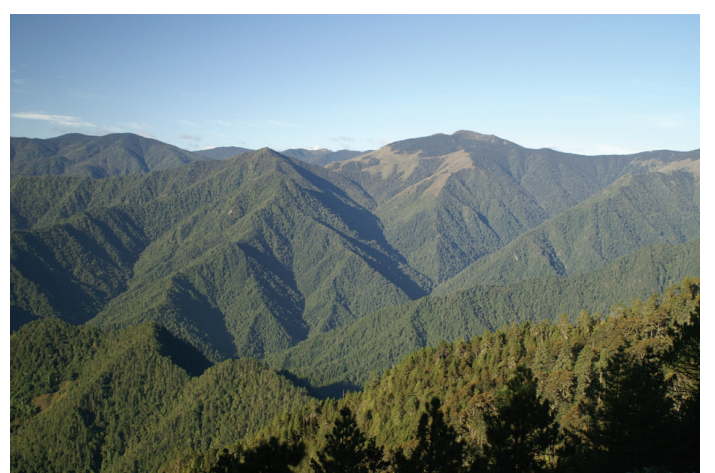

FIGURE 1: Study site Samage near the village of Gehuaqing in the Baimaxueshan Nature Reserve, Yunnan, China. The highest peak is Mount Samage (4166 m).

within the core area of the range of the study group at $3200 \mathrm{~m}$ ). Temperature and precipitation varied markedly with seasons (for details on climate, see [11]). Several habitat types have been identified at the study site, ranging from subtropical evergreen forest in valleys, pine forest on lower slopes, mixed deciduous, and evergreen conifer forest, with bamboo and rhododendron featuring in the shrub layer. Pure fir forest tends to take over from mixed forest (with spruce, hemlock, and firs as the dominant gymnosperms) above ca $3500 \mathrm{~m}$ [4]. Parts of the Samage Forest have been selectively logged, and various human activities, such as, grazing of cattle and goats and harvest of nontimber forest products were still taking place inside the reserve when this research was carried out.

Over the course of the study, we obtained a total of 1900 location records (altitude and geographical coordinates) of the group's center every $30 \mathrm{~min}$ using a GPS receiver (Garmin eTrex Summit). The group's center was determined by visually estimating the spread of the group and taking the midpoint. Climate data collection is described in $\mathrm{Li}$ et al. [4]. Phenology data were collected by inspecting 157 food trees for the presence or absence of fruits and young leaves on a monthly basis (for details see [4]). We visually assessed lichen biomass of trees in $67400 \mathrm{~m}^{2}$ plots, and each tree was assigned a lichen load factor ranging from 0 (none) to 4 (heavy) (see [4]). Data on monthly dietary composition was gathered via instantaneous group scans at 15 or $30 \mathrm{~min}$ intervals. For each scanned individual that was feeding, we recorded the food type, namely, lichens, young leaves, mature leaves, buds, flowers, fruits/seeds, and others (for details, see [11]).

We constructed a general linear model with mean monthly group altitude used as the response and dependence on lichens (as measured by the percentage of lichen in diet) as the main predictor and ambient temperature at research site, fruit, and young leaf availability as control predictors. Mean monthly temperature and total monthly rainfall were rather strongly correlated $\left(r_{p}=0.72\right)$, so we excluded rainfall from model. Linear models were run in JMP, and correlations were conducted using the function cor.test in $R$ [15]. 


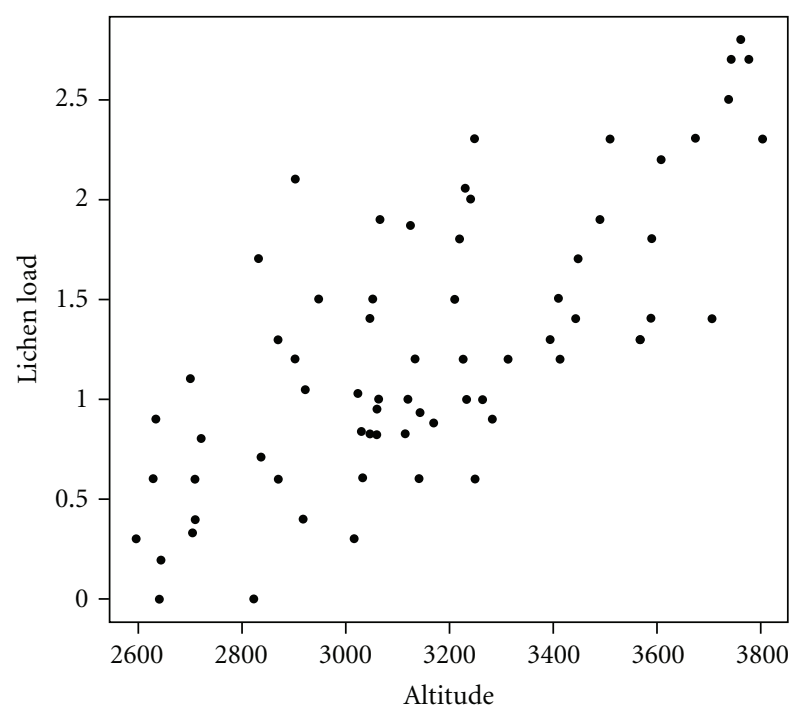

FIGURe 2: Lichen load per $400 \mathrm{~m}^{2}$ plot correlated with altitude (in $\mathrm{m}$ above seal level).

TABle 1: GLM with monthly use of altitude as the response and temperature, fruit availability, young leaf availability and the reliance on lichen as predictors (whole model test: $F=3.5173, R^{2}=$ $0.484, P=0.0324)$.

\begin{tabular}{lccc}
\hline Predictors & Estimate & $t$ ratio & $P$ \\
\hline Temperature $\left({ }^{\circ} \mathrm{C}\right)$ & 0.0010141 & 0.78 & 0.4490 \\
Fruit availability & 0.0003114 & 1.39 & 0.1845 \\
Young leaf availability & 0.0002704 & 1.46 & 0.1661 \\
\% lichen in diet & 0.0004584 & 2.54 & 0.0229 \\
\hline
\end{tabular}

\section{Results}

Lichen load of trees was significantly higher at higher altitudes (Kendall's $\tau, \tau=0.5348714, z=6.3229, P$ value $=$ $2.567 e-10$; Figure 2), where the proportion of conifer to broadleaf trees is more biased [4].

The mean monthly altitude used by the focal group was $3270 \mathrm{~m}$ (SD $129 \mathrm{~m}$ ). The monthly minimum was $3060 \mathrm{~m}$ in April 06 and the monthly maximum was 3550 in July 07. Neither climatic factors nor the availability of flush and fruit had an effect on the monthly use of altitudes. The monkeys' degree of dependence on lichen was the only predictor that had a significant effect on the monthly use of altitudes (Table 1).

\section{Discussion}

There has been no compelling evidence for an effect of climate on the use of altitudes in snub-nosed monkeys inhabiting montane forests in the north-temperate zone [3-8]. Black-and-white snub-nosed monkeys are unusual among primates in their colonization of marginal habitats and unique in their dietary specialization $[11,12]$. The ability to digest lichens and extract energy from them enables them endure winter when there is a severe shortage of plant foods
[11]. The present findings show that the degree of lichen use best explains the pattern of altitudinal ranging and resolves the paradox of lack of downward migration in winter, as lichen abundance linearly increases with altitude. The fact that lichens are rich in nonstructural carbohydrates [12] may counterbalance any thermoregulatory stress incurred from staying at high altitude. Fan and Jiang [16] found for another montane subtropical-temperate primate population that it was not temperature but food distribution that was the driving force behind the altitudinal ranging patterns of the group. While the sunshine hypothesis of Quan et al. [6] may explain microhabitat use within the winter range of snubnosed monkeys (but see [17]), it does not determine use of high altitudes in the first place.

\section{Acknowledgments}

Permission to work at Baimaxueshan Nature Reserve was given by Sikang Liu. For assistance in the field the author are most grateful to Shunkai Feng ("Lao Feng"), Xuesheng Feng, and Xuewen Feng. Financial support for this work was generously provided by Janggen-Pöhn-Stiftung, A. H. Schultz Stiftung, Zürcher Tierschutz, G. \& A. ClarazSchenkung, Goethe-Stiftung, Kommission für Reisestipendien der Schweizerischen Akademie der Naturwissenschaften SANW, Offield Family Foundation, Primate Conservation, Inc., Zoological Society of San Diego, and the Primate Action Fund of Conservation International.

\section{References}

[1] E. R. Loft, J. W. Menke, and T. S. Burton, "Seasonal movements and summer habitats of female black-tailed deer," Journal of Wildlife Management, vol. 48, pp. 1317-1325, 1984.

[2] S. Luccarini, L. Mauri, S. Ciuti, P. Lamberti, and M. Apollonio, "Red deer (Cervus elaphus) spatial use in the Italian Alps: home range patterns, seasonal migrations, and effects of snow and winter feeding," Ethology Ecology and Evolution, vol. 18, no. 2, pp. 127-145, 2006.

[3] R. C. Kirkpatrick and Y. C. Long, "Altitudinal ranging and terrestriality in the Yunnan snub-nosed monkey (Rhinopithecus bieti)," Folia Primatologica, vol. 63, pp. 102-106, 1994.

[4] D. Li, C. C. Grueter, B. Ren et al., "Ranging of Rhinopithecus bieti in the Samage Forest, China. II. Use of land cover types and altitudes," International Journal of Primatology, vol. 29, no. 5, pp. 1147-1173, 2008.

[5] T. Zhong, L. Xiao, S. Huo, Z. Xiang, W. Xiao, and L. Cui, "Altitudinal range of black-and-white snub-nosed monkeys (Rhinopithecus bieti) at Baima Snow Mountain, China," Zoological Research, vol. 29, pp. 181-188, 2008.

[6] R. Quan, G. Ren, J. E. Behm et al., "Why does Rhinopithecus bieti prefer the highest elevation range in winter? A test of the sunshine hypothesis," PLoS ONE, vol. 6, Article ID e24449, 2011.

[7] K. Niu, C. L. Tan, and Y. Yang, "Altitudinal movements of Guizhou snub-nosed monkeys (Rhinopithecus brelichi) in Fanjingshan National Nature Reserve, China: implications for conservation management of a flagship species," Folia Primatologica, vol. 81, no. 4, pp. 233-244, 2010.

[8] C. L. Tan, S. Guo, and B. Li, "Population structure and ranging patterns of Rhinopithecus roxellana in Zhouzhi National 
Nature Reserve, Shaanxi, China," International Journal of Primatology, vol. 28, no. 3, pp. 577-591, 2007.

[9] A. J. Marshall and R. W. Wrangham, "Evolutionary consequences of fallback foods," International Journal of Primatology, vol. 28, no. 6, pp. 1219-1235, 2007.

[10] Z. F. Xiang, S. Huo, W. Xiao, R. C. Quan, and C. C. Grueter, "Diet and feeding behavior of Rhinopithecus bieti at Xiaochangdu, Tibet: adaptations to a marginal environment," American Journal of Primatology, vol. 69, no. 10, pp. 1141$1158,2007$.

[11] C. C. Grueter, D. Li, B. Ren, F. Wei, Z. Xiang, and C. P. van Schaik, "Fallback foods of temperate-living primates: a case study on snub-nosed monkeys," American Journal of Physical Anthropology, vol. 140, no. 4, pp. 700-715, 2009.

[12] R. C. Kirkpatrick, Ecology and behavior of the yunnan SnubNosed langur (Rhinopithecus bieti, Colobinae) [Ph.D. dissertation], University of California, Davis, Calif, USA, 1996.

[13] S. C. Alberts, J. Hollister-Smith, R. Mututua et al., "Seasonality and long-term change in a savanna environment," in Seasonality in Primates, D. K. Brockman and C. P. van Schaik, Eds., pp. 157-195, Cambridge University Press, Cambridge, UK, 2005.

[14] A. J. Marshall, C. M. Boyko, K. L. Feilen, R. H. Boyko, and M. Leighton, "Defining fallback foods and assessing their importance in primate ecology and evolution," American Journal of Physical Anthropology, vol. 140, no. 4, pp. 603-614, 2009.

[15] R Development Core Team, "R: a language and environment for statistical computing," in $R$ Foundation for Statistical Computing, Vienna, Austria, 2010.

[16] P. F. Fan and X. L. Jiang, "Altitudinal ranging of black-crested gibbons at Mt. Wuliang, Yunnan: effects of food distribution, temperature and human disturbance," Folia Primatologica, vol. 81, no. 1, pp. 1-9, 2010.

[17] Y. Li, Z. Jiang, C. Li, and C. C. Grueter, "Effects of seasonal folivory and frugivory on ranging patterns in Rhinopithecus roxellana," International Journal of Primatology, vol. 31, no. 4, pp. 609-626, 2010. 

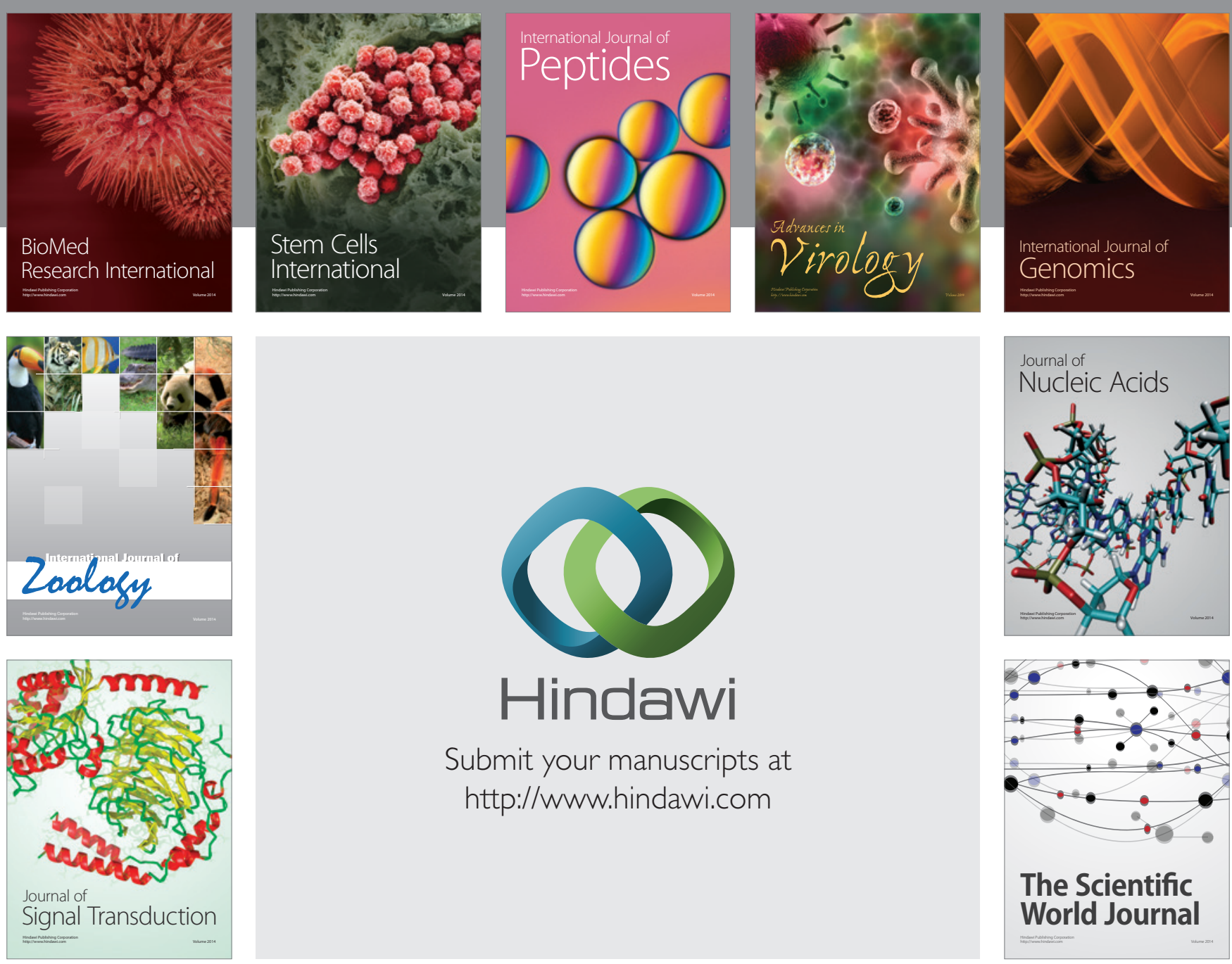

Submit your manuscripts at

http://www.hindawi.com
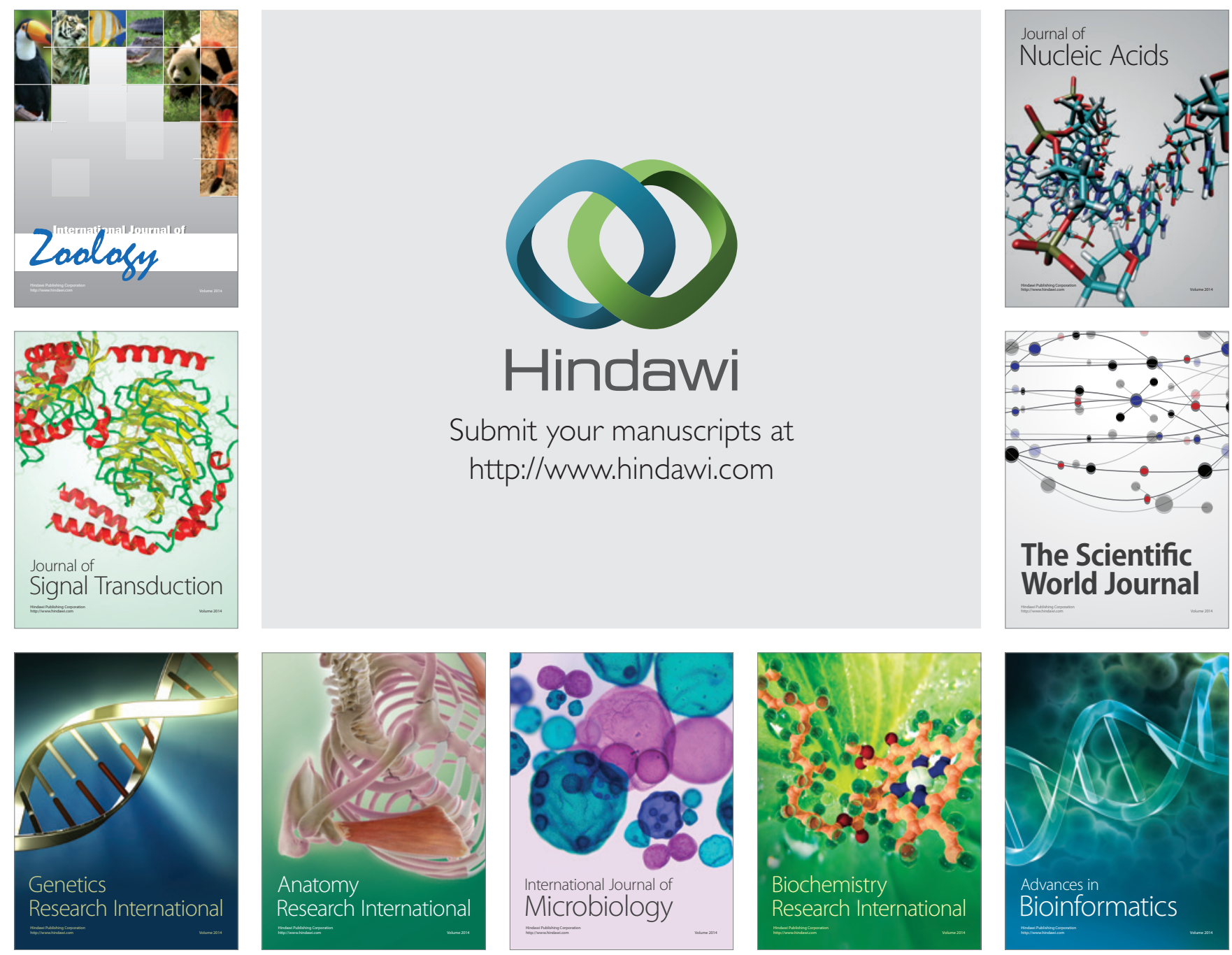

The Scientific World Journal
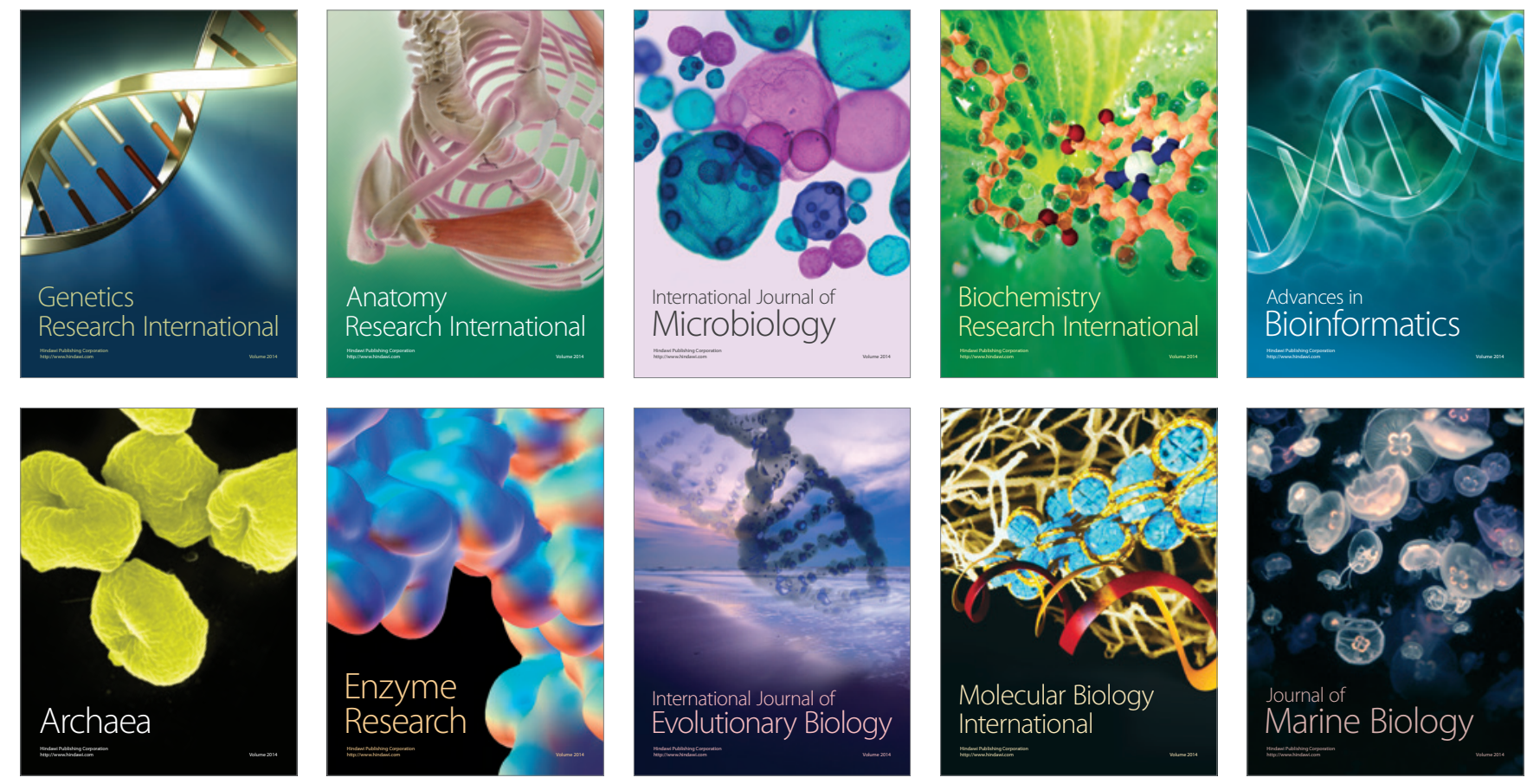